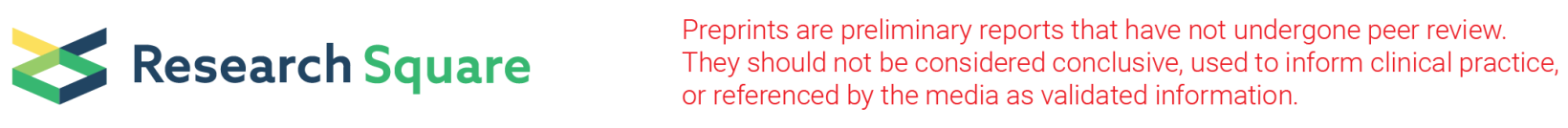

\title{
Phenotype - Chemotype Correlation of the Herb Bletilla Rchb. f. Based on a Comprehensive Evaluation of Thirty- Three Geographic Populations
}

\author{
Junfeng Huang \\ Wuhan Botanical Garden \\ Fang Yuan \\ Wuhan Botanical Garden \\ Ming Zhou \\ Wuhan Botanical Garden \\ Tianyue Huang \\ Wuhan Botanical Garden \\ Yanjun Zhang \\ Wuhan Botanical Garden \\ Qiong Liang ( $\sim$ qiongl@wbgcas.cn) \\ Wuhan Botanical Garden
}

\section{Research Article}

Keywords: Active ingredients, Bletilla, correlation analysis, Gray relation analysis, Phenotypic traits

Posted Date: October 21st, 2021

DOI: https://doi.org/10.21203/rs.3.rs-933584/v1

License: @ (i) This work is licensed under a Creative Commons Attribution 4.0 International License. Read Full License 


\section{Abstract \\ Background}

The Bletilla genus of Orchidaceae includes plants with great economic value, among which $B$. striata is the main traditional medicinal plant, and its pseudobulb, known as BaiJi, was first recorded in Shennong's Classic of Materia Medica. However, there has been little systemic evaluation of the germplasm quality of Bletilla plants in China. In order to comprehensive evaluate the Bletilla resources in China and screen out the candidate phenotypic traits determining yield and/or quality of Bletilla, the variation of phenotypic indicators (pseudobulb, leaf, stem, inflorescence, flower) and active ingredients contents (polysaccharide, total phenolics and militarine) in different populations of $B$. striata and $B$. ochracea were investigated through 4 years' common-garden experiment.

\section{Results}

There were abundant phenotypic variations and significant differences among different populations in the morphological phenotypes, pseudobulb weight and main active ingredient contents. Five populations, including HNSZ, AHBZ, HBLT, HBSN and JSNJ, showed good prospects for industrial development, presenting higher quality in terms of yield and main active ingredient content. Pseudobulb yield, polysaccharide and total phenol content are positively correlated with phenotypic traits. Militarine content is negatively correlated with almost all indexes. Plant height, leaf width and stem diameter may be important indicators of potential excellent germplasms.

\section{Conclusions}

Bletilla is not strictly geoauthentic medicinal plants. $B$. ochracea could be accepted as an alternative resource to $B$. striata. The best harvest period of Bletilla is the third year after cultivation. Plant height, leaf width and stem diameter may be important indicators of potential excellent germplasms. These results provide important information required for the efficient screening and utilization of Bletilla germplasm resources.

\section{Background}

Bletilla Rchb. f. (Orchidaceae) is a small genus with six species distributed in Asia from northern Myanmar and southern and eastern China to Japan and Korea. China is the distribution center of Bletilla with four species: $B$. sinensis (Rolfe) Schltr., B. formosana (Hayata) Schltr., B. striata (Thunb. ex A. Murray) Rchb. f. and B. ochracea Schltr. [1] (http://www.iplant.cn/info/Bletilla?t=foc). B. striata is the main traditional medicinal plant, and its pseudobulb, recorded as BaiJi in the Chinese Pharmacopeia, was first recorded in Shennong's Classic of Materia Medica [2]. B. ochracea and B. formosana are also used as local medications or substitutes [3]. Currently, Bletilla research is focus mainly on chemical components, pharmacological activities and reproductive techniques, while there has been little systemic evaluation of the germplasm quality of Bletilla plants in China [4-9].

B. striata polysaccharide (BSP) is rich in the dried pseudobulb with content of $20-50 \%[10,11]$. As the main active ingredient, BSP is widely used in clinical hemostasis, and can also be used as an excellent biopolymer material and pharmaceutical excipient [12-14]. Moreover, approximately 211 compounds have been extracted from $B$. striata pseudobulbs, including glucosides, bibenzyls, phenanthrenes, quinones, stilbenes, triterpenoids, phenolics etc. [5, 9, 1516]. Militarine (1,4-bis [4-(glucooxy) benzyl]-2-isobutyl malate $\left(\mathrm{C}_{34} \mathrm{H}_{46} \mathrm{O}_{17}\right)$ ) shows the highest content in the nonpolysaccharide fraction in $B$. striata [17], with content ranging from $1.45 \%$ to $9.28 \%$ [18]. BSP and militarine are suggested quality markers for $B$. striata [3, 19]. Additionally, phenolics are important active compounds in $B$. striata, and the total phenol content varied from $1.83 \%$ to $13.73 \%$.

Common garden experiments retaining the same cultural environment can be used to analyze phenotypic variation among different populations to eliminate phenotypic variation induced by environmental factors and have become an important means of resource evaluation [20-22]. Through the collection of wild resources for common garden cultivation, quality evaluation was performed to determine the high-quality resources in the tested varieties and has been widely used in many medicinal plants, such as Epimedium sagittatum and Lycium chinense [22, 23]. Gray relation analysis (GRA) is a multifactor statistical analysis method that includes dimensionless processing, correlation coefficient calculation, correlation degree and relative correlation degree calculation and is widely used in the comprehensive evaluation of the quality of medicinal materials [24]. The correlation is used in the context of a linear relationship between 2 continuous variables and the Pearson correlation coefficient is typically used for jointly normally distributed data [25]. Correlation analysis can be used to measure the relationship among yield, quality and agronomic traits to determine which trait affects yield and/or quality [26, 27].

In this study, we selected 33 Bletilla populations to systematically evaluate the main phenotypic traits, pseudobulb yields and main active ingredients among different species and populations. We aimed to screen higher-quality germplasm resources of Bletilla and the key indicators related to economic characteristics, which will provide important information for the efficient breeding of $B$. striata. Our study will enhance our ongoing efforts in the sustainable development of traditional medicinal plants.

\section{Results}

\section{Morphological measurement and resource evaluation of pseudobulb weight}

The morphological phenotypes of the aboveground parts of 33 populations (including $28 \mathrm{~B}$. striata populations and $5 \mathrm{~B}$. ochracea populations) were measured for three years (Fig. 1; Additional file 2). Statistical analysis showed that there were abundant phenotypic variations and significant differences 
among different populations, especially the plant height, leaf blade length, stem diameter and inflorescence height with high $\mathrm{F}$ values and extremely low $P$ values (Table 1). The plant height, leaf blade length, inflorescence height and length of $B$. ochracea were greater than those of $B$. striata. In addition to leaf blade length in $B$. striata, the plant height, leaf blade length and width of $B$. striata and $B$. ochracea increased with increasing planting years, while the fruit number decreased in B. ochracea and B. striata (Fig. 2a).

Table 1 Summary of the main statistical parameters in the one-way ANOVA of phenotypic traits and the main active ingredient contents 


\begin{tabular}{|c|c|c|c|c|c|c|c|c|}
\hline & & Min & Max & Mean & CV (\%) & $\mathrm{F}$ & $P$ & $\mathrm{n}$ \\
\hline \multirow[t]{3}{*}{ Plant height (cm) } & 2018 & 5 & 57 & 25.79 & 38.61 & 19.62 & $1.08 \mathrm{E}-72$ & 621 \\
\hline & 2019 & 10 & 80 & 29.78 & 28.26 & 27.26 & 2.89E-85 & 482 \\
\hline & 2020 & 13 & 68 & 32.32 & 33.33 & 53.19 & 1.14E-150 & 617 \\
\hline \multirow[t]{3}{*}{ Leaf blade length (cm) } & 2018 & 7 & 55 & 29.79 & 24.99 & 15.99 & $1.61 \mathrm{E}-60$ & 621 \\
\hline & 2019 & 10 & 54 & 30.02 & 24.16 & 31.67 & 7.39E-95 & 482 \\
\hline & 2020 & 10 & 64 & 30.21 & 27.71 & 33.28 & 3.67E-110 & 617 \\
\hline \multirow[t]{3}{*}{ Leaf blade width (cm) } & 2018 & 1.0 & 12.5 & 4.51 & 40.00 & 22.83 & $2.15 \mathrm{E}-82$ & 617 \\
\hline & 2019 & 2.0 & 9.5 & 4.85 & 28.99 & 26.51 & $1.49 \mathrm{E}-83$ & 482 \\
\hline & 2020 & 2.0 & 11.5 & 5.16 & 27.66 & 23.13 & $2.84 \mathrm{E}-83$ & 617 \\
\hline \multirow[t]{3}{*}{ Leaf number } & 2018 & 1 & 6 & 3.69 & 19.79 & 5.87 & $3.49 \mathrm{E}-20$ & 621 \\
\hline & 2019 & 2 & 8 & 4.30 & 23.41 & 11.51 & $6.83 \mathrm{E}-41$ & 482 \\
\hline & 2020 & 2 & 43 & 4.01 & 43.04 & 1.53 & $3.26 \mathrm{E}-02$ & 617 \\
\hline \multirow[t]{3}{*}{ Stem diameter (mm) } & 2018 & 0.33 & 9.86 & 5.31 & 33.84 & 15.69 & $1.75 \mathrm{E}-59$ & 621 \\
\hline & 2019 & 2.13 & 11.36 & 5.44 & 26.19 & 32.96 & $1.72 \mathrm{E}-97$ & 482 \\
\hline & 2020 & 2.08 & 9.85 & 5.75 & 23.05 & 21.41 & 4.17E-78 & 617 \\
\hline \multirow[t]{3}{*}{ Inflorescence height (cm) } & 2018 & 15 & 71 & 39.83 & 29.67 & 13.65 & $1.35 \mathrm{E}-38$ & 326 \\
\hline & 2019 & 10 & 89 & 32.11 & 35.96 & 37.76 & $2.58 \mathrm{E}-105$ & 470 \\
\hline & 2020 & 19 & 83 & 40.35 & 27.98 & 37.33 & 2.05E-119 & 616 \\
\hline \multirow[t]{3}{*}{ Inflorescence length (cm) } & 2018 & 11 & 63 & 32.08 & 33.57 & 13.69 & $9.76 \mathrm{E}-39$ & 327 \\
\hline & 2019 & 10 & 69 & 30.27 & 30.51 & 31.96 & 2.81E-94 & 470 \\
\hline & 2020 & 12 & 58 & 32.51 & 28.55 & 33.26 & 4.91E-110 & 616 \\
\hline \multirow[t]{3}{*}{ Flower number } & 2018 & 3 & 17 & 9.00 & 33.27 & 5.19 & $6.49 \mathrm{E}-14$ & 325 \\
\hline & 2019 & 1 & 14 & 5.85 & 46.54 & 26.98 & $1.49 \mathrm{E}-83$ & 469 \\
\hline & 2020 & 3 & 17 & 8.83 & 25.70 & 20.16 & 5.61E-74 & 611 \\
\hline \multirow[t]{3}{*}{ Fruit number } & 2018 & 1 & 9 & 2.60 & 51.26 & 1.47 & $6.85 \mathrm{E}-02$ & 244 \\
\hline & 2019 & 1 & 5 & 1.47 & 47.06 & 3.70 & $5.89 \mathrm{E}-09$ & 280 \\
\hline & 2020 & 3 & 3 & 1.49 & 50.59 & 7.46 & $1.14 \mathrm{E}-20$ & 263 \\
\hline \multirow[t]{4}{*}{ Weight of pseudobulb (g) } & 2017 & 1.4 & 111.0 & 34.27 & 69.55 & 38.75 & 1.23E-93 & 370 \\
\hline & 2018 & 3.2 & 281.1 & 81.92 & 66.25 & 12.05 & 1.37E-05 & 278 \\
\hline & 2019 & 6.7 & 725.0 & 138.97 & 72.34 & 13.21 & $2.55 \mathrm{E}-22$ & 286 \\
\hline & 2020 & 5.8 & 597.0 & 185.32 & 71.06 & 14.28 & $5.29 \mathrm{E}-89$ & 270 \\
\hline \multirow[t]{4}{*}{ Polysaccharide content (\%) } & 2017 & 18.36 & 59.38 & 45.03 & 18.92 & 604.53 & $0.00 \mathrm{E}+00$ & 99 \\
\hline & 2018 & 15.36 & 60.00 & 45.66 & 18.68 & 740.31 & $0.00 \mathrm{E}+00$ & 99 \\
\hline & 2019 & 12.37 & 59.60 & 46.94 & 21.03 & 880.41 & 1.37E-34 & 99 \\
\hline & 2020 & 8.34 & 55.31 & 42.84 & 27.16 & 2343.25 & 3.01E-02 & 99 \\
\hline \multirow[t]{4}{*}{ Total phenol content (\%) } & 2017 & 1.57 & 4.84 & 3.73 & 21.00 & 481.12 & $3.84 \mathrm{E}-05$ & 99 \\
\hline & 2018 & 1.36 & 5.07 & 3.63 & 22.61 & 427.51 & $1.42 \mathrm{E}-33$ & 99 \\
\hline & 2019 & 0.84 & 4.97 & 3.77 & 23.47 & 334.64 & $0.00 \mathrm{E}+00$ & 99 \\
\hline & 2020 & 1.21 & 5.01 & 3.42 & 29.48 & 312.33 & $0.00 \mathrm{E}+00$ & 99 \\
\hline \multirow[t]{4}{*}{ Militerane content (\%) } & 2017 & 0.45 & 3.99 & 1.44 & 46.62 & 602.31 & $6.51 \mathrm{E}-38$ & 99 \\
\hline & 2018 & 0.51 & 3.68 & 1.43 & 45.93 & 670.60 & $2.38 \mathrm{E}-01$ & 99 \\
\hline & 2019 & 0.55 & 3.11 & 1.51 & 40.05 & 469.44 & 1.67E-02 & 99 \\
\hline & 2020 & 0.69 & 4.29 & 1.60 & 44.19 & 284.97 & 7.44E-38 & 99 \\
\hline
\end{tabular}


Min and Max, the minimum value and maximum value in the sample; Mean, the average value of the sample; CV (\%), coefficient of variation; $\mathrm{F}$, ratio of MSA/MSE; $P$, $P$ value; $\mathrm{n}$, sample size.

Comparison of morphological measurements (a), pseudobulb weight (b) and the main active ingredient content (c) in different growth stages and different species of $B$. striata and B. ochracea. Values are the mean \pm SD (standard deviation), and different lowercase letters indicate significant differences with the parameter of $P<0.05$.

There were significant differences in pseudobulb weight among different species and different populations, and the coefficient of variation (CV) of pseudobulb weight was higher than the CVs of other phenotypic traits (Fig. 2, Table 1). In detail, the weight of the one-year-old pseudobulb of different populations varied from 5.02 to 86.08 (g), and the CV (\%) was 69.55. The GXHZ, HBXG, HBLT, HBMC and HBWH populations were ranked as the top five, while the last five populations were HBXS, HBSY, HBWF (B. ochracea), SXXX, and GXLY. For the two-year-old pseudobulb, the weight in different populations varied from 12.58 to 176.35 (g), and the CV (\%) was 66.25. GXHZ, HBXG, HBLT, AHBZ and GZZY were ranked as the top five populations, while the last five populations were SCLS, HBSY, HBWF (B. ochracea), SXXX and GXLY. For the three-year-old pseudobulb, the weight in different populations varied from 23.13 to $329.42(\mathrm{~g})$, and the CV (\%) was 72.34. GXHZ, AHBZ, HBXG, HBLT and HBSN were ranked as the top five populations, while the last five populations were SYZS, HBSY, HBWF (B. ochracea), SXXX, and GXLY. For the four-year-old pseudobulb, the weight in the different populations varied from 31.63 to 442.77 (g), and the CV (\%) was 71.06. HBLT, AHBZ, HBWH, HBSN and HBXG were ranked as the top five populations, while the HBWF (B. ochracea), HBSY, SXXX, HNCL and GXLY populations showed lower weights. In general, except in GXHZ, HNCL and SCWY, the weight of the pseudobulbs increased with the growing period, while the average annual growth rates of the pseudobulb were 2.42, 1.69 and 1.31, respectively, showing a decreasing trend. There was a significant difference between the two species, and the average one-, two-, three- and four-year-old pseudobulb weights of B. ochracea were 19.66, 63.26, 102.07 and 140.95 (g), which were lower than the $37.44,85.72,144.79$ and 193.49 (g) of B. striata, respectively (Table 2, Fig. 2a).

Table 2 The fresh weight of pseudobulbs of 28 populations of $B$. striata and 5 populations of $B$. ochracea 


\begin{tabular}{|c|c|c|c|c|c|}
\hline No. & Population code & 1-year-old (2017) & 2-year-old (2018) & 3-year-old (2019) & 4-year-old (2020) \\
\hline 1 & $\mathrm{GXHZ}$ & $86.08 \pm 13.29^{a}$ & $176.35 \pm 78.70^{a}$ & $329.42 \pm 219.32^{a}$ & $285.73 \pm 177.13^{c}$ \\
\hline 2 & GXLY & $5.02 \pm 3.07^{k}$ & $12.58 \pm 7.58^{n}$ & $23.13 \pm 13.11^{i}$ & $31.6316 .53^{\mathrm{m}}$ \\
\hline 3 & YNBS & $18.45 \pm 11.58^{h i j}$ & $52.16 \pm 10.50^{\mathrm{jklmn}}$ & $100.95 \pm 36.55^{\mathrm{ghi}}$ & $167.60 \pm 40.73^{\text {efghi }}$ \\
\hline 4 & GZZY & $59.77 \pm 28.91^{c}$ & $152.43 \pm 32.84^{\mathrm{abc}}$ & $253.88 \pm 20.81^{b c}$ & $283.08 \pm 34.85^{\mathrm{cd}}$ \\
\hline 5 & HNLS & $44.43 \pm 11.07^{d}$ & $98.21 \pm 30.68^{\text {efghi }}$ & $133.16 \pm 57.66^{\mathrm{efg}}$ & $212.06 \pm 158.28^{\text {def }}$ \\
\hline 6 & HNSZ & $15.55 \pm 5.97^{\mathrm{hij}}$ & $67.42 \pm 51.50^{\mathrm{ijkl}}$ & $131.45 \pm 71.33^{\text {efgh }}$ & $186.64 \pm 90.39^{\text {defgh }}$ \\
\hline 7 & $\mathrm{HNCL}$ & $36.55 \pm 11.74^{\text {def }}$ & $68.55 \pm 19.58^{\mathrm{ijkl}}$ & $66.52 \pm 27.34^{\mathrm{hi}}$ & $36.89 \pm 20.47^{\mathrm{m}}$ \\
\hline 8 & YCWZ & $39.67 \pm 19.23^{d}$ & $80.14 \pm 20.82^{g h i j}$ & $199.36 \pm 64.48^{\mathrm{cd}}$ & $254.91 \pm 79.04^{\text {cde }}$ \\
\hline 9 & SCLS & $21.24 \pm 6.14^{\mathrm{ghi}}$ & $36.07 \pm 16.49^{1 \mathrm{mn}}$ & $69.70 \pm 32.87^{\mathrm{hi}}$ & $80.33 \pm 14.79 \mathrm{jijkm}$ \\
\hline 10 & SCWY & $26.66 \pm 11.81^{\mathrm{fgh}}$ & $125.10 \pm 39.67^{\text {bcde }}$ & $108.91 \pm 32.24^{\mathrm{fgh}}$ & $75.51 \pm 45.11^{\mathrm{ijklm}}$ \\
\hline 11 & HBYL & $37.56 \pm 6.41^{\text {de }}$ & $78.95 \pm 21.01^{\mathrm{ghij}}$ & $141.17 \pm 34.41^{\text {defg }}$ & $194.37 \pm 72.01^{\text {defg }}$ \\
\hline 12 & HBLC & $39.45 \pm 13.33^{d}$ & $103.59 \pm 40.97^{\text {defgh }}$ & $136.05 \pm 36.46^{\mathrm{efg}}$ & $153.30 \pm 45.66^{f g h i}$ \\
\hline 13 & HBXE & $24.48 \pm 5.80^{g h}$ & $73.74 \pm 44.13^{\mathrm{hijk}}$ & $94.49 \pm 36.70^{g h i}$ & $110.01 \pm 58.34^{\mathrm{ijklm}}$ \\
\hline 14 & SYZS & $24.41 \pm 6.79 \mathrm{gh}$ & $45.02 \pm 28.37^{\mathrm{klmn}}$ & $61.25 \pm 41.19^{\mathrm{hi}}$ & $97.80 \pm 25.16^{\mathrm{ijk} \mathrm{jm}}$ \\
\hline 15 & HBHF & $39.79 \pm 16.95^{d}$ & $68.82 \pm 41.16^{\mathrm{ijkl}}$ & $132.21 \pm 63.03^{\mathrm{efg}}$ & $213.68 \pm 92.48^{\text {def }}$ \\
\hline 16 & HBXS & $15.24 \pm 4.52^{h i j k}$ & $62.84 \pm 28.88^{\mathrm{jklm}}$ & $93.2755 .52^{\mathrm{ghi}}$ & $130.48 \pm 54.36^{\text {fghij }}$ \\
\hline 17 & HBJS & $30.10 \pm 11.40^{\text {efg }}$ & $57.99 \pm 40.33^{\mathrm{jklm}}$ & $94.61 \pm 38.39^{g h i}$ & $152.47 \pm 50.05^{\text {fghi }}$ \\
\hline 18 & HBSN & $36.23 \pm 6.81^{\text {def }}$ & $131.69 \pm 27.26^{\mathrm{bcd}}$ & $263.91 \pm 68.91^{\mathrm{b}}$ & $367.12 \pm 89.39^{a b}$ \\
\hline 19 & HBWH & $64.41 \pm 20.01^{c}$ & $119.97 \pm 15.68^{\text {bcdef }}$ & $193.36 \pm 90.63^{\text {cde }}$ & $399.53 \pm 116.89^{a b}$ \\
\hline 20 & xSSC & $15.73 \pm 9.21^{\mathrm{hij}}$ & $53.82 \pm 11.89^{\mathrm{jklm}}$ & $80.64 \pm 8.71^{\mathrm{ghi}}$ & $110.45 \pm 33.88^{\mathrm{hijklm}}$ \\
\hline 21 & HBJM & $18.84 \pm 2.45^{\text {hij }}$ & $48.38 \pm 12.00^{\mathrm{jklmn}}$ & $99.00 \pm 21.87^{\mathrm{ghi}}$ & $117.80 \pm 37.57^{\mathrm{hijkl}}$ \\
\hline 22 & HBXG & $84.92 \pm 15.84^{a}$ & $162.78 \pm 55.11^{\mathrm{ab}}$ & $299.58 \pm 33.65^{a b}$ & $333.50 \pm 49.51^{\mathrm{bc}}$ \\
\hline 23 & HBMC & $68.03 \pm 17.15^{\mathrm{bc}}$ & $109.06 \pm 38.18^{\text {cdefg }}$ & $185.71 \pm 46.99^{\text {cde }}$ & $254.60 \pm 103.59^{\text {cde }}$ \\
\hline 24 & HBLT & $77.35 \pm 14.76^{\mathrm{ab}}$ & $158.96 \pm 39.57^{\mathrm{ab}}$ & $286.61 \pm 44.59^{\mathrm{ab}}$ & $442.77 \pm 78.20^{a}$ \\
\hline 25 & HBSY & $13.47 \pm 3.62^{\mathrm{ijk}}$ & $28.49 \pm 10.05^{\mathrm{mn}}$ & $40.58 \pm 17.27^{i}$ & $62.82 \pm 30.8 \mathrm{gjklm}^{\mathrm{j}}$ \\
\hline 26 & AHBZ & $46.18 \pm 19.93^{d}$ & $152.93 \pm 59.94^{\mathrm{abc}}$ & $305.60 \pm 58.49^{a b}$ & $401.42 \pm 97.18^{a b}$ \\
\hline 27 & JSNJ & $42.08 \pm 16.98^{d}$ & $121.91 \pm 41.78^{\text {bcdef }}$ & $182.00 \pm 69.76^{\mathrm{de}}$ & $210.09 \pm 80.87^{\text {def }}$ \\
\hline 28 & SXXX & $9.20 \pm 2.33^{\mathrm{jk}}$ & $15.72 \pm 13.22^{n}$ & $36.14 \pm 22.81^{i}$ & $38.29 \pm 31.72^{\mathrm{klm}}$ \\
\hline 29 & HNLS & $20.32 \pm 7.00^{\mathrm{hi}}$ & $94.38 \pm 53.56^{\text {fghi }}$ & $163.38 \pm 81.45^{\text {def }}$ & $199.00 \pm 111.81^{\text {def }}$ \\
\hline 30 & HNSZ & $15.68 \pm 6.39^{h i j}$ & $45.89 \pm 25.53^{\mathrm{klmn}}$ & $91.74 \pm 17.76^{\mathrm{ghi}}$ & $128.95 \pm 74.95^{\mathrm{fghijk}}$ \\
\hline 31 & HBWF & $9.81 \pm 6.42^{\mathrm{jk}}$ & $17.78 \pm 7.92^{\mathrm{mn}}$ & $38.68 \pm 26.01^{i}$ & $53.75 \pm 35.43^{\mathrm{jklm}}$ \\
\hline 32 & SCLS & $28.86 \pm 7.33^{\mathrm{fg}}$ & $73.47 \pm 36.30^{\mathrm{jk}}$ & $87.41 \pm 56.11^{\mathrm{ghi}}$ & $124.77 \pm 85.79^{g h i j k}$ \\
\hline 33 & SXZP & $21.74 \pm 4.66^{\mathrm{ghi}}$ & $55.81 \pm 18.35^{\mathrm{jklm}}$ & $110.90 \pm 13.73^{\mathrm{fgh}}$ & $158.60 \pm 22.78^{\text {fghi }}$ \\
\hline
\end{tabular}

No. 1-28 are B. striata, No. 29-33 are B. ochracea. Red represents the top five populations of pseudobulb weight in different years, while green represents the last five populations. Values represent the mean \pm SD of ten individuals, and different lowercase letters with superscripts indicate significant differences between populations with the parameter of $P<0.05$. 
The polysaccharide, total phenol and militarine contents of pseudobulbs were determined among different species and populations. The results showed that significant differences were observed among different populations, with a minimum F value of 284.97 and $P$ values much lower than 0.05 (Table 1 ). Overall, there were no differences in the content of the main active ingredients among different species and different planting years (Fig. 2c).

Most populations had an excellent phenotype in terms of polysaccharide content, which varied from 8.52 to 59.77 (\%). 8, 12, 15 and 13 populations accounted for more than $50 \%$ of the one-, two-, three- and four-year-old pseudobulbs, and 17, 12,13 and 9 populations ranged from $40 \%$ to $50 \%$, respectively (Table 3 ). The average polysaccharide contents of one-, two-, three- and four-year-old pseudobulbs of $B$. ochracea were $45.18,47.57,44.70$ and 40.45 (\%), and the average polysaccharide contents of one-, two-, three- and four-year-old pseudobulbs of $B$. striata were $45.00,45.32,47.34$ and 42.92 (\%), which means the content of polysaccharide in pseudobulb of $B$. striata was three-year-old $>$ two-year-old $>$ one-year-old $>$ four-year-old, while which of $B$. ochracea was two-yearold > one-year-old > three-year-old > four-year-old (Fig. 2C). In general, the top five populations with the highest polysaccharide content in the pseudobulbs of the average of four years were HBYL, SXZP (B. ochracea), AHBZ, HBHF and HBWF (B. ochracea), while the last five populations were GXLY, HNLS ( $B$. ochracea), HBJM, HNSZ (B. ochracea) and YNBS.

Obvious variation was observed in the content of total phenol, which varied from 0.90 to 5.00 (\%). There were $14,11,16$ and 13 populations that were higher than $4 \%$ of the one-, two-, three- and four-year-old pseudobulbs, and $12,15,12$ and 12 populations ranged from $3 \%$ to $4 \%$, respectively (Table 3 ). The average total phenol content of one-, two-, three- and four-year-old pseudobulbs of B. ochracea were 3.96, 3.57, 3.89 and 3.35 (\%), which were lower than the 3.98, 4.14, 4.33 and 3.43 of $B$. striata, respectively. Therefore, the order of the contents of total phenol in the pseudobulb of $B$. striata was three-year-old $>$ two-year-old $>$ one-year-old $>$ four-year-old, while that in $B$. ochracea was one-year-old $>$ three-year-old $>$ two-year-old $>$ four-year-old (Fig. $2 c$ ). In general, the top five populations with the highest average total phenol contents in pseudobulbs of four years were JSNJ, HBYL, HBXG, SCWY and HBLT, while the last five populations were YCWZ, HNLS (B. ochracea), SXXX, YNBS and HBJM.

Table 3 Active ingredient contents of 28 populations of $B$. striata and 5 populations of $B$. ochracea (listed at the end of the document)

The average milliarine contents of the one-, two-, three- and four-year-old pseudobulbs of $B$. ochracea were $1.43,1.62,1.85$ and 1.64 (\%), which were generally higher than those of $B$. striata $(1.44,1.39,1.45$ and $1.60(\%)$, respectively). That is, the order of the militarine contents of the pseudobulbs of $B$. striata was four-year-old $>$ three-year-old $>$ one-year-old $>$ two-year-old, while that in B. ochracea was three-year-old $>$ four-year-old $>$ two-year-old $>$ one-year-old (Fig. 2c). Militarine contents varied from 0.51 to 4.12 (\%), 4, 4, 6 and 5 populations accounted for more than $2 \%$ of the one-, two-, three- and four-year-old pseudobulbs, and $7,5,9$ and 12 populations accounted for $1.5 \%$ to $2 \%$, respectively (Table 3 ). Overall, the top five populations with the highest average militarine contents of the pseudobulbs of four years were HNSZ, SCLS (B. ochracea), HBWF (B. ochracea), YCWZ and SXXX, while the HBHF, HNCL, HBMC, HBXG and SXZP ( $B$. ochracea) populations were the five populations with the lowest contents.

GRA of the pseudobulb weight, pseudobulb growth ratio and main active ingredient content showed that there are 2 populations greater than 0.6 and 15 populations greater than 0.5. HNSZ, AHBZ, HBLT, HBSN and JSNJ were ranked as the top five, indicating that these populations have good characteristics in comprehensive yield and quality, while the last five populations were SXXX, SYZS, GXLY, HBJM and YNBS (Table 4).

Table 4 Correlation degree and rank of pseudobulb weight and main active ingredient contents based on gray relational analysis 


\begin{tabular}{|c|c|c|c|c|}
\hline \multirow{2}{*}{$\begin{array}{l}\text { Population } \\
\text { code }\end{array}$} & \multicolumn{2}{|c|}{ Correlation degree } & \multirow{2}{*}{$\begin{array}{l}\text { Relative } \\
\text { correlation } \\
\text { degree }\end{array}$} & \multirow[t]{2}{*}{ Rank } \\
\hline & $\begin{array}{l}\text { relative to } \\
\text { optimal seq. }\end{array}$ & $\begin{array}{l}\text { relative to } \\
\text { least seq. }\end{array}$ & & \\
\hline HNSZ & 0.721 & 0.432 & 0.625 & 1 \\
\hline AHBZ & 0.683 & 0.434 & 0.611 & 2 \\
\hline HBLT & 0.676 & 0.471 & 0.589 & 3 \\
\hline HBSN & 0.631 & 0.452 & 0.583 & 4 \\
\hline JSNJ & 0.628 & 0.465 & 0.574 & 5 \\
\hline GXHZ & 0.635 & 0.501 & 0.559 & 6 \\
\hline HBWH & 0.611 & 0.483 & 0.558 & 7 \\
\hline SCLS (B. ochracea) & 0.607 & 0.485 & 0.556 & 8 \\
\hline HBXG & 0.649 & 0.525 & 0.553 & 9 \\
\hline HBYL & 0.639 & 0.532 & 0.545 & 10 \\
\hline SCWY & 0.608 & 0.508 & 0.545 & 11 \\
\hline GZZY & 0.566 & 0.505 & 0.528 & 12 \\
\hline HBXS & 0.577 & 0.522 & 0.525 & 13 \\
\hline SXZP (B. ochracea) & 0.595 & 0.558 & 0.516 & 14 \\
\hline HNLS & 0.552 & 0.538 & 0.506 & 15 \\
\hline HBLC & 0.528 & 0.518 & 0.505 & 16 \\
\hline $\mathrm{HBHF}$ & 0.571 & 0.568 & 0.501 & 17 \\
\hline HBWF (B. ochracea) & 0.574 & 0.575 & 0.500 & 18 \\
\hline XSSC & 0.525 & 0.533 & 0.496 & 19 \\
\hline YCWZ & 0.488 & 0.531 & 0.479 & 20 \\
\hline HBMC & 0.531 & 0.590 & 0.474 & 21 \\
\hline HNLS (B. ochracea) & 0.501 & 0.571 & 0.467 & 22 \\
\hline SCLS & 0.515 & 0.597 & 0.463 & 23 \\
\hline HBXE & 0.476 & 0.593 & 0.445 & 24 \\
\hline HNSZ (B. ochracea) & 0.467 & 0.599 & 0.438 & 25 \\
\hline $\mathrm{HNCL}$ & 0.494 & 0.652 & 0.431 & 26 \\
\hline HBJS & 0.451 & 0.612 & 0.424 & 27 \\
\hline HBSY & 0.445 & 0.633 & 0.413 & 28 \\
\hline SXXX & 0.446 & 0.655 & 0.405 & 29 \\
\hline SYZS & 0.438 & 0.646 & 0.404 & 30 \\
\hline GXLY & 0.440 & 0.665 & 0.398 & 31 \\
\hline HBJM & 0.406 & 0.694 & 0.369 & 32 \\
\hline YNBS & 0.409 & 0.757 & 0.351 & 33 \\
\hline
\end{tabular}

The populations of unmarked species are $B$. striata.

\section{Correlation analysis of phenotypic traits, pseudobulb weight and active ingredient content}

To investigate which phenotypic traits may determine the yield of pseudobulb and active ingredient content, and whether there is a correlation between the yield of pseudobulb and active ingredient content, Pearson correlation analysis was performed for two-, three- and four-year-old plants among 13 indexes, including 9 morphological indexes of aboveground parts, pseudobulb weight indexes and 3 active ingredient indexes. The results showed that except for the negative correlation between the militarine content and other indexes, the other 12 indexes were positively correlated (Fig. 3).

The correlation coefficient of plants in 2018 ranged from -0.401 to 0.861 . The correlation coefficients between plant height and leaf blade length, and between inflorescence height and inflorescence length were greater than 0.8 ( 0.806 and 0.861 , respectively). There were 4 other correlation coefficients greater than 0.7 , 3 correlation coefficients greater than $0.6,5$ correlation coefficients greater than 0.5 , and 7 correlation coefficients greater than 0.4 , and all of them showed 
extremely significant differences with $P$ values of less than 0.01 . Overall, there were significant correlations between phenotypic traits except leaf number, flower number and fruit number. There were significant correlations between pseudobulb weight and plant height, leaf blade width, stem diameter, and total phenol content. There were significant correlations between polysaccharide content and leaf blade width, stem diameter, and total phenol content. There were significant correlations between the total phenol content and leaf blade width, stem diameter, pseudobulb weight, and polysaccharide content. There was a significant negative correlation between militarine content and leaf blade length (Fig. 3a).

The correlation coefficient of plants in 2019 ranged from -0.282 to 0.920 . The correlation coefficient of inflorescence height and inflorescence length was 0.920. The correlation coefficients of plant height with inflorescence height and inflorescence length were greater than 0.8 . There were 6 other correlation coefficients greater than $0.7,7$ correlation coefficients greater than 0.6 , and 7 correlation coefficients greater than 0.5 , and all of them had extremely significant differences with a $P$ value less than 0.01 . Overall, there were significant correlations between phenotypic traits except leaf number, and fruit number. There were significant correlations between pseudobulb weight and all phenotypic traits except for fruit number; however, the three indexes with the strongest correlations were the same as those in 2018 , which were plant height, leaf width and stem diameter. The correlation between polysaccharide content and phenotypic traits was lower than that in 2018 , and the same trends were observed for total phenol and militerine. However, there was still a significant correlation between the polysaccharide and total phenol content (Fig. 3b).

The correlation coefficient of plants in 2020 ranged from -0.331 to 0.931 , and the highest value was obtained for inflorescence height and inflorescence length. There were 2 other correlation coefficients greater than $0.8,3$ correlation coefficients greater than $0.7,6$ correlation coefficients greater than 0.6 , and 6 correlation coefficients greater than 0.5 , and all of them had extremely significant differences with a $P$ value less than 0.01 . Overall, there were significant correlations between phenotypic traits except leaf number and fruit number. There were significant correlations between pseudobulb weight and plant height, leaf blade width, leaf number, and stem diameter. There were significant correlations between polysaccharide content and leaf blade width, stem diameter, total phenol content. There were significant correlations between the total phenol content and leaf blade width, and polysaccharide content. There was also a nearly negative correlation between the militarine content and other indexes (Fig. 3c).

\section{Discussion}

In the cultivation of $B$. striata, regardless of the pseudobulb reproduction and direct seed sowing, most of the provenances are wild resources, which are usually applied in the original cycle of harvesting in situ, reserving seeds in situ and replanting in situ, without systematic population selection and breeding [3]. Through comprehensive investigation and collection of Bletilla genus resources in China to establish a germplasm resource nursery, which can be used for resource quality evaluation and correlation analysis based on the important agronomic traits and pharmacodynamic components, and which will play an important role in the breeding of excellent varieties. Previous small-scale collection and resource evaluation of Bletilla populations were carried out. Zhu et al. performed a systematic evaluation on 13 indexes from three aspects (ornamental characteristics, adaptability, and cultivation and management) in 12 populations in nine provinces of China, and established a comprehensive evaluation model for Bletilla genus resource plants. Furthermore, Chinese researchers also evaluated the germplasm resources of $B$. formosana in Yunnan Province, determined the total phenol content of $B$. striata in Northwest Hubei Province, and determined the polysaccharide content of $B$. striata from different areas in Anhui and Guizhou Provinces. To evaluate the quality differences, fuzzy matter-element analysis and gray pattern recognition analysis were used to analyze the contents of extract, polysaccharide, militarine and total phenol of 30 populations of B. striata from main producing areas in Guizhou Province [7]. In this study, 33 Bletilla populations (including 28 B. striata populations and 5 B. ochracea populations), which covered their major distribution areas in China, were used for resource quality evaluation. This is the largest and most comprehensive evaluation of $B$. striata and $B$. ochracea in China at present.

Stable yield and quality are the most important value indicators of medicinal materials, and good germplasm resources are the basis for ensuring the quality of medicinal materials. In our research, we continuously evaluated the main value species, including B. striata and B. ochracea, for 4 years. Based on our yearly results, we screened excellent populations with higher yields in terms of four-year-old pseudobulb weight (Table 2) and higher contents of polysaccharide, total phenol and militarine compounds, respectively (Table 3), indicating that these populations were good germplasm resources for the single-component utilization of Bletilla. Furthermore, HNSZ, AHBZ, HBLT, HBSN and JSNJ populations showed good characteristics in terms of pseudobulb weight, the pseudobulb growth ratio and the main active ingredients contents according to GRA, indicating that these populations showed higher quality, with good values of all the indicators (Table 4). Bletilla is widely distributed in China, and it is not strictly geoauthentic medicinal. Therefore, different geographical populations from different provinces may have good quality and are excellent germplasm resources. Chen et al. also found that Bletilla from different provinces of China have similar HPLC fingerprints, and were classified into one group by cluster analysis [28]. In addition, even in the same region, there may be a large difference between different geographical populations. Western Hubei Province is rich in forest resources, which provide good ecological conditions for the breeding and reproduction of medicinal plants. We collected the HBXS, HBSN, XSSC and HBYL populations near the Shennongjia Forestry District and the HBLC, HBXE, HBHF, HBJS and HBWF (B. ochracea) populations near the Enshi Tujia and Miao Autonomous Prefecture. We found that there were differences in the weight of pseudobulbs and the contents of three active ingredients among different populations, whether near Shennongjia Forest District or Enshi Tujia and Miao Autonomous Prefecture, and there were abundant variations among populations. For example, the weights of the pseudobulbs of the HBXS and XSSC populations were significantly lower than those of HBSN, and the polysaccharide and total phenol contents in HBXS were higher than those in HBSN. The content of militerine was highest in HBLC, while that in HBXE and HBHF was very low, and the HBHF population had high contents of polysaccharide and total phenol. The determination of total polyphenol in B. striata from 16 areas of northwestern of Hubei Province showed that the content of total polyphenol varied in different areas. The analysis of the polysaccharide content of 18 samples of $B$. formosana from 8 populations in Baoshan City of Yunnan Province showed that there were significant differences among different samples. The polysaccharide contents of $B$. striata from different areas of Guizhou and Anhui Province were also significantly different [18]. All these studies showed that it is necessary to understand the resource distribution, habitat and situation of Bletilla and then to evaluate germplasm resources, which can provide a theoretical basis for the protection and utilization of Bletilla. 
Traditionally, although other species of Bletilla are also used as local medicinal plants, $B$. striata is the only species officially approved for use [3]. Considering the high medicinal value, high demand and gradually diminishing wild resources of $B$. striata, to protect traditional resources and develop new medicinal plant resources, it is necessary to conduct in-depth research on $B$. striata and its related species, to excavate alternative resources of $B$. striata and reduce the waste of effective ingredients and resources. However, the distribution of $B$. sinensis is narrow and limited to the south of Yunnan Province in China. The pseudobulb size of $B$. formosana is significantly smaller than the pseudobulb size of $B$. ochracea and $B$. striata, and the polysaccharide content of $B$. formosana was slightly lower than the polysaccharide content of $B$. ochracea and B. striata [29]. The pseudobulbs of $B$. ochracea are larger, and its flowering period is later than the flowering period of $B$. striata. Currently, Bletilla is widely planted as a bonsai plant, so in addition to ornamental plants, can underground pseudobulbs of $B$. ochracea also be harvested as medicinal plants? We chose 5 populations of $B$. ochracea and 28 populations of $B$. striata to demonstrate the phenotypic quality of $B$. striata with higher average pseudobulbs weights, while there was no difference between the two species in terms of polysaccharide, total phenol and militarine contents. These results suggested that $B$. ochracea could be accepted as an alternative resource to $B$. striata.

Efficient screening of excellent genetic resources is important for new germplasm creation and breeding, and efficiently discovering the phenotypic indicators significantly related to yield and quality is especially critical for perennial herbs [30]. Usually, B. striata exhibits the best comprehensive traits and is harvested in the third year after cultivation [31,32], which requires at least 3 years to estimate the genetic material and preliminarily screen out a quality germplasm. In this paper, Pearson correlation analysis of two-, three- and four-year-old plants showed that there were significant correlations between pseudobulb weight and other phenotypic traits, especially plant height, leaf blade width and stem diameter, which implies that plants with excellent growth can produce better pseudobulb yields (Fig. 3). Interestingly, there was a strong significant correlation between the polysaccharide and total phenol contents, and polysaccharide and total phenol showed a similar trend to pseudobulb yield, which was significantly related to leaf blade width and stem diameter. These results may provide important and more direct indicators for quickly screening and breeding potential good germplasms. The uncommon positive correlation between yield and the main quality factors may provide hopeful prospects for excellent germplasm breeding of Bletilla herbs; of course, this positive relation and the genetic foundation of this relation need further demonstration and in-depth investigation [26]. In addition, the militarine content was almost negatively correlated with other indexes, which indicated that the accumulation of militarine may occur more often under the condition of limited growth, and further research is needed to reveal the synthesis and metabolic mechanisms of militarine in Bletilla plants. Next, integrating phenomics, genomics and metabonomics approaches for high-throughput mining of the key phenotypes and revealing the genetic mechanism is our aim in recent years.

The growth capacity of yield characteristics can also be selected to evaluate different genetic resources. Populations of HBSN, HBWH, and AHBZ showed excellent yield phenotypes with high yield and growth capacity, and the pseudobulb weight of the HBSN population could even reach 7.29 and 10.13 times in the third and fourth years after cultivation, respectively. Other populations such as HNSZ, SXZP ( $B$. ochracea), HBXS, and HBJM, also showed a good growth capacity. Our results indicated that the mean annual growth ratios of pseudobulbs in 3 years were $2.42,1.69$ and 1.31, which gradually decreased with the cultivation years. Even in some populations, such as GXHZ, HNCL and SCWY, the pseudobulb weight in the fourth or even third year began to decrease. Yearly content variation showed that the average contents of both polysaccharides and total phenol in the one-, two-, three- and four-year-old pseudobulbs of Bletilla varied in the following order: three years old > two years old > one year old > four years old, which confirmed the conclusion regarding the best harvest period of Bletilla [31, 32]. However, the average militarine content of one-, two-, three- and four-year-old pseudobulbs of Bletilla varied in the following order: four-yearold > three-year-old > one-year-old > two-year-old, which again indicated differences in polysaccharide and total phenol, and the synthesis and metabolic mechanisms of militarine in Bletilla plants need to be revealed.

\section{Conclusion}

There were abundant phenotypic variations and significant differences among different populations in the morphological phenotypes, pseudobulb weight and main active ingredient contents. Bletilla is not strictly geoauthentic medicinal plants. Excellent germplasm resources may be distributed in distant geographical locations. There may be a large difference between different geographical populations even in the same region. $B$. ochracea could be accepted as an alternative resource to $B$. striata. Five populations, including HNSZ, AHBZ, HBLT, HBSN and JSNJ, showed good prospects for industrial development, presenting higher quality in terms of yield and main active ingredient content. Pseudobulb yield, polysaccharide and total phenol content are positively correlated with phenotypic traits. Militarine content is negatively correlated with almost all indexes. Plant height, leaf width and stem diameter may be important indicators of potential excellent germplasms. The best harvest period of Bletilla is the third year after cultivation. These results provide important information required for the efficient screening and utilization of Bletilla germplasm resources.

\section{Methods}

\section{Experimental material}

Thirty-three natural populations of Bletilla (including 28 B. striata populations and 5 B. ochracea populations) were randomly collected from its main natural range across ten provinces in China (Additional file 1; Fig. 1). In 2017, 30 individuals of new pseudobulb of the year with similar size were collected from each population without affecting the continuous growth of wild resources and transported to a germplasm resources nursery in the Wuhan Botanical Garden (WBG) of the Chinese Academy of Sciences (CAS) for common-garden cultivation with the same soil formula of $20 \%$ sand, $30 \%$ humus and $50 \%$ garden soil.

WBG is an institution for species conservation and scientific research. The ex-situ conservation of plant resources is the main job of WBG. Introducing species from other area only requires a work certification issued by WBG and does not require government or local administrative permission. The representative specimens of plants from each population were identified by XiaoDong Li and deposited in the herbarium (HIB) of WBG. The collected samples are only for scientific research and comply with the guidelines of WBG.

\section{Phenotypic measurements}


The weight of the pseudobulb was measured and marked as one-year-old in winter 2017. The morphology of the aboveground parts and the weight of the pseudobulbs of 10 individuals were measured every year for the next three years (2018-2020).

The recorded morphological parameters of the aboveground parts included plant height $(\mathrm{cm})$, leaf blade length $(\mathrm{cm})$, leaf blade width (cm), total leaf number, stem diameter $(\mathrm{mm})$, inflorescence height $(\mathrm{cm})$, inflorescence length $(\mathrm{cm})$, total flower number and total fruit number. Leaf phenotypes and stem diameter were measured in August or September. Plant height was the vertical distance between the top of the highest leaf and the ground. Leaf length and leaf width were measured using the largest leaf. The phenotypes of the inflorescences were measured in April or May. Inflorescence height was the vertical distance from the base to the tip of the inflorescence stem.

In early November 2018, the withered aboveground parts of 10 individuals were removed, and the pseudobulbs (two years old) were excavated and cleaned to measure the weight. The corresponding fraction of pseudobulbs was removed for the subsequent determination of polysaccharide, total phenol and militarine content. The same method was used to measure the weight of pseudobulbs in 2019 (three years old) and in 2020 (four years old) using the other 10 individuals.

\section{Polysaccharide content analysis}

After removing the fibrous roots, the sampled pseudobulbs were sliced, steamed in a water bath, and dried in the shade according to the Chinese Pharmacopeia. Dried pseudobulb slices were crushed for polysaccharide content, total phenol content and militarine content analyses. All the samples were collected in early November 2017, 2018, 2019 and 2020.

The phenol-sulphuric acid method was used to analyze polysaccharide content as described previously with minor modifications [23]. Approximately $2 \mathrm{~g}$ of dried pseudobulb powder was treated with $50 \mathrm{~mL} \mathrm{H} 2 \mathrm{O}$ for $120 \mathrm{~min}$ at $100^{\circ} \mathrm{C}$ twice using the conventional heating reflux extraction method. The $100 \mathrm{~mL}$ extract was concentrated to $10 \mathrm{~mL}$ by rotary evaporation, $25 \mathrm{~mL}$ of $95 \%$ ethanol solution was added to half of the extract solution ( $5 \mathrm{~mL}$ ) for precipitation, and they had to rest overnight at room temperature. After centrifugation ( $3000 \mathrm{rpm} / \mathrm{min})$ for $15 \mathrm{~min}$, the precipitate was dissolved in $25 \mathrm{~mL} \mathrm{H}_{2} \mathrm{O}$ to obtain the crude polysaccharide solution and quantified by the phenol-sulfuric acid method. $10 \mathrm{mg}$ of standard glucose was dissolved in $100 \mathrm{~mL} \mathrm{H}_{2} \mathrm{O}$ at a concentration of $100 \mu \mathrm{g} / \mathrm{mL}$ and diluted to six different concentrations of $0,20,40,60,80$ and $100 \mu \mathrm{g} / \mathrm{mL} .1 \mathrm{~mL}$ glucose solution, $1 \mathrm{~mL} 5 \%$ phenol and $6 \mathrm{~mL}$ concentrated sulfuric acid were added into a plug test tube in turn. After shaking and mixing, the samples were left at $25^{\circ} \mathrm{C}$ for 40 min, and the absorbance was determined at $484 \mathrm{~nm}\left(\mathrm{~A}_{484}\right)$. The regression equation was $\mathrm{A}_{484}=0.0088 \mathrm{C}(\mu \mathrm{g} / \mathrm{mL})+0.0122, \mathrm{r}=0.9998(\mathrm{n}=6)$. Then, 1 mL polysaccharide solution was measured by the same method as glucose solution. The absorbance was compared with the regression equation, multiplied by the dilution multiple (50) and divided by the weight of dried pseudobulb powder. The results were expressed as polysaccharide content (\%).

\section{Total phenol content analysis}

The sampling procedure was the same as above. Total phenol content was determined by Folin-Ciocalteu's phenol reagent [33]. Gallic acid was used as the standard to draw the regression equation, and $100 \mathrm{mg}$ gallic acid was dissolved in $100 \mathrm{~mL} 60 \%$ ethanol at a concentration of $1000 \mu \mathrm{g} / \mathrm{mL}$ and diluted to five different concentrations of $10,20,30,40$ and $50 \mu \mathrm{g} / \mathrm{mL}$. Then, $1 \mathrm{~mL}$ of gallic acid solution and $5 \mathrm{~mL} 10 \%(\mathrm{v} / \mathrm{v})$ Folin-Ciocalteu's phenol reagent were added into a test tube to react for $10 \mathrm{~min}$, and $5 \mathrm{~mL} 2 \%(\mathrm{~m} / \mathrm{v}) \mathrm{Na}_{2} \mathrm{CO}_{3}$ was added. After shaking, the sample was allowed to rest at $25^{\circ} \mathrm{C}$ for $1 \mathrm{~h}$, and the absorbance of each sample was determined at $760 \mathrm{~nm}\left(\mathrm{~A}_{760}\right)$. The regression equation was $\mathrm{A}_{760}=0.0132 \mathrm{C}(\mu \mathrm{g} / \mathrm{mL})-0.0004, \mathrm{r}=0.9999(\mathrm{n}=6)$. Approximately $2 \mathrm{~g}$ dried pseudobulb powder was treated with $80 \mathrm{~mL} 60 \%$ ethanol for $120 \mathrm{~min}$ at $90^{\circ} \mathrm{C}$ by using the conventional heating reflux extraction method. Cooling down to RT, the solution was made up to $80 \mathrm{ml}$ with $60 \%$ ethanol and then filtered using filter paper. The residue was extracted with $60 \%$ ethanol again, and the filtrates were mixed as the test solution, which was measured by the same method as the standard sample, to obtain the $A_{760}$, compared with the regression equation, multiplied by the dilution multiple (160) and divided by the weight of dried pseudobulb powder. The results were expressed as total phenol content (\%).

\section{Militarine content analysis}

The sampling procedure was the same as above. HPLC was used to measure the militarine content according to the Chinese Pharmacopeia 2020 edition. 11.4 g millitarine was dissolved in $6 \mathrm{ml} 52.9 \%$ ethanol to obtain a $1.9 \mathrm{mg} / \mathrm{mL}$ standard solution, which was diluted to six different concentrations of 1900,950 , 475 , $237.5,118.75$ and $59.375 \mu \mathrm{g} / \mathrm{mL}$. The standard solutions were analyzed by reversed-phase HPLC using a mobile phase of acetonitrile and water with $0.1 \%$ phosphoric acid (elution ratio: 22:78, v/v; wavelength: $223 \mathrm{~nm}$; flow rate: $1 \mathrm{~mL} / \mathrm{min}$; injection volume: $10 \mu \mathrm{L}$ ) and the column oven temperature was set at $30^{\circ} \mathrm{C}$. The regression equation of the standard curve was peak area $=22287199 \mathrm{C}(\mu \mathrm{g} / \mathrm{mL})+137858, \mathrm{r}=1(\mathrm{n}=6)$. Approximately $0.2 \mathrm{~g}$ dried pseudobulb powder was extracted with $25 \mathrm{ml} 52.9 \%$ ethanol at $30^{\circ} \mathrm{C}$ for $30 \mathrm{~min}$ by an ultrasound system (power $=300 \mathrm{~W}$, frequency $=37 \mathrm{~Hz}$ ). The solution was brought up to $25 \mathrm{ml}$ with $52.9 \%$ ethanol and then filtered through filter paper. The filtrate was analyzed by the same method as the standard sample, compared with the regression equation, multiplied by the dilution multiple (25000) and divided by the weight of the dried pseudobulb powder. Ultimately, the results were expressed as militarine content (\%).

\section{Gray relation analysis}

The means of the values in Table 2 and Table 3 were used as the raw data for GRA. For pseudobulb weight, in addition to considering the weight of the pseudobulb measured directly in every year, pseudobulb growth ratios of one, two and three years were also used as indexes. A total of 19 indexes constituted the evaluation matrix, $\left\{X_{i k}\right\}(i=1,2,3, \ldots \mathrm{m} ; \mathrm{k}=1,2,3, \ldots \mathrm{n}, \mathrm{m}=33, \mathrm{n}=19)$ and calculated the average value $\left(X_{K}\right)$ of each index. The original data were normalized by the formula $Y_{i k}=X_{i k} / X_{K}$. The maximum and minimum values of each index were selected as the optimal $\left\{Y_{s k}\right\}$ and the least $\left\{Y_{t k}\right\}$ reference sequences respectively. The correlation coefficients relative to the optimal and the least reference sequences were calculated with the formulas $(\Delta$ min + 
$\rho \Delta \max ) /\left(Y_{s k}-Y_{i k}+\rho \Delta \max \right)$ and $(\Delta \min +\rho \Delta \max ) /\left(Y_{i k}-Y_{t k}+\rho \Delta \max \right)$, respectively, where $\rho$ is the discrimination coefficient, and its value is generally approximately $0.5, \Delta \min =\min \left|Y_{s k}-Y_{i k}\right|, \Delta \max =\max \left|Y_{s k}-Y_{i k}\right|$. The uniform average of the correlation coefficient in each index was used to calculate the correlation degree relative to the optimal and the least reference sequences, which is expressed as $r_{i(s)}$ and $r_{i(t)}$, respectively. The relative correlation degree $\left(r_{i}\right)$ of the evaluation matrix $\left\{X_{i k}\right\}$ relative to the optimal and least reference sequences was defined as $r_{i}=r_{i(s)} /\left(r_{i(s)}+r_{i(t)}\right)$, which wes used to rank (Table 4$)$.

\section{Correlation analysis}

The means of the values in Additional file 2, Table 2 and Table 3 were used to calculate the Pearson correlation coefficient with IBM SPSS Statistics 25 software, which was used to construct a heat map in Microsoft Office Excel 2019. * or ** represent significant differences with the parameters of $P<0.05$ and $P<0.01$, respectively.

\section{Data analysis}

Two-tailed ANOVA was performed to test significant differences in measured variables among different populations and different growth years. ANOVA and Pearson correlation analysis were carried out with IBM SPSS Statistics 25.

Table 3 Active ingredient contents of 28 populations of $B$. striata and 5 populations of $B$. ochracea 


\begin{tabular}{|c|c|c|c|c|c|c|c|c|c|}
\hline \multirow[t]{2}{*}{ No. } & \multirow{2}{*}{$\begin{array}{l}\text { Population } \\
\text { code }\end{array}$} & \multicolumn{4}{|c|}{ Polysaccharide content (\%) } & \multicolumn{4}{|c|}{ Total phenol content (\%) } \\
\hline & & 2017 & 2018 & 2019 & 2020 & 2017 & 2018 & 2019 & 2020 \\
\hline 1 & $\mathrm{GXHZ}$ & $45.70 \pm 0.31^{1}$ & $50.32 \pm 0.33^{\mathrm{ef}}$ & $50.77 \pm 0.65^{j}$ & $48.64 \pm 0.05^{h}$ & $3.98 \pm 0.023^{1}$ & $4.47 \pm 0.051^{d}$ & $3.88 \pm 0.047^{1 \mathrm{~m}}$ & $4.09 \pm 0.020^{e f}$ \\
\hline 2 & GXLY & $35.26 \pm 0.67^{r}$ & $37.64 \pm 0.50^{\mathrm{m}}$ & $39.37 \pm 0.27^{s}$ & $20.80 \pm 0.39^{u}$ & $3.00 \pm 0.065^{\mathrm{qr}}$ & $3.04 \pm 0.016^{\circ}$ & $3.32 \pm 0.032^{\circ}$ & $1.39 \pm 0.025^{\mathrm{rs}}$ \\
\hline 3 & YNBS & $18.84 \pm 0.48^{t}$ & $15.91 \pm 0.50^{\mathrm{p}}$ & $12.97 \pm 0.60^{v}$ & $8.52 \pm 0.16^{v}$ & $2.14 \pm 0.053^{t}$ & $1.41 \pm 0.049^{r}$ & $0.90 \pm 0.057^{t}$ & $1.26 \pm 0.034^{\mathrm{rs}}$ \\
\hline 4 & GZZY & $47.84 \pm 0.52^{\mathrm{hi}}$ & $45.95 \pm 0.68^{i}$ & $47.89 \pm 0.52^{m}$ & $46.48 \pm 0.14^{j}$ & $4.01 \pm 0.053^{h i}$ & $3.86 \pm 0.039 \mathrm{gh}$ & $3.94 \pm 0.081^{\mathrm{ijkl}}$ & $3.82 \pm 0.207^{h i j}$ \\
\hline 5 & HNLS & $46.37 \pm 1.02^{\mathrm{jkl}}$ & $51.75 \pm 0.34^{d}$ & $56.16 \pm 0.65^{e f}$ & $51.12 \pm 0.21^{\text {ef }}$ & $3.53 \pm 0.057^{\circ}$ & $4.09 \pm 0.051^{f}$ & $4.19 \pm 0.040^{f g}$ & $3.78 \pm 0.026^{\mathrm{ijk}}$ \\
\hline 6 & HNSZ & $41.01 \pm 0.64^{\circ}$ & $44.80 \pm 0.38^{j}$ & $48.86 \pm 0.83^{\prime}$ & $39.90 \pm 0.33^{n}$ & $3.91 \pm 0.068^{h i j}$ & $3.62 \pm 0.077^{\mathrm{klm}}$ & $4.49 \pm 0.053^{c d}$ & $4.07 \pm 0.126^{e f}$ \\
\hline 7 & HNCL & $47.80 \pm 0.83^{\mathrm{hi}}$ & $48.17 \pm 0.21^{\mathrm{g}}$ & $46.18 \pm 0.26^{n}$ & $49.85 \pm 0.17^{g}$ & $3.88 \pm 0.079^{\mathrm{kl}}$ & $3.92 \pm 0.105^{\mathrm{gh}}$ & $3.58 \pm 0.034^{n}$ & $3.96 \pm 0.057^{f g h}$ \\
\hline 8 & YCWZ & $36.84 \pm 0.69^{q}$ & $39.86 \pm 0.73^{\prime}$ & $40.95 \pm 0.44^{\mathrm{qr}}$ & $40.55 \pm 0.12^{n}$ & $2.67 \pm 0.053^{s}$ & $3.01 \pm 0.078^{\circ}$ & $2.79 \pm 0.1167^{q r}$ & $2.16 \pm 0.101^{\mathrm{p}}$ \\
\hline 9 & SCLS & $49.82 \pm 0.49^{g}$ & $50.14 \pm 0.36^{\text {ef }}$ & $50.72 \pm 0.66^{\mathrm{j}}$ & $51.66 \pm 0.32^{\mathrm{e}}$ & $3.62 \pm 0.063^{n}$ & $3.65 \pm 0.043^{\mathrm{jkl}}$ & $3.90 \pm 0.086^{\mathrm{klm}}$ & $4.03 \pm 0.070^{\text {efg }}$ \\
\hline 10 & SCWY & $53.43 \pm 0.99^{e}$ & $50.30 \pm 0.50^{\text {ef }}$ & $53.52 \pm 0.56^{\mathrm{gh}}$ & $50.73 \pm 1.26^{f}$ & $4.52 \pm 0.060^{\mathrm{ab}}$ & $4.10 \pm 0.072^{f}$ & $4.38 \pm 0.085^{\mathrm{de}}$ & $4.08 \pm 0.050^{e f}$ \\
\hline 11 & HBYL & $57.96 \pm 0.52^{b}$ & $59.77 \pm 0.35^{a}$ & $55.61 \pm 0.34^{f}$ & $53.20 \pm 0.12^{c}$ & $4.77 \pm 0.073^{a}$ & $4.92 \pm 0.148^{a}$ & $4.30 \pm 0.032^{e f}$ & $4.04 \pm 0.073^{\mathrm{efg}}$ \\
\hline 12 & HBLC & $43.73 \pm 0.61^{\mathrm{m}}$ & $39.73 \pm 0.34^{\prime}$ & $47.76 \pm 0.45^{\mathrm{m}}$ & $38.69 \pm 0.52^{\circ}$ & $3.75 \pm 0.055^{\mathrm{m}}$ & $3.81 \pm 0.050^{\mathrm{hi}}$ & $4.49 \pm 0.043^{\mathrm{cd}}$ & $3.88 \pm 0.088^{g h i}$ \\
\hline 13 & HBXE & $41.82 \pm 0.53^{\text {no }}$ & $41.86 \pm 0.57^{\mathrm{k}}$ & $41.59 \pm 1.28^{q r}$ & $36.99 \pm 0.25^{p}$ & $3.85 \pm 0.083^{j k}$ & $3.61 \pm 0.076^{\mathrm{klm}}$ & $3.78 \pm 0.222^{\mathrm{m}}$ & $3.49 \pm 0.035^{\mathrm{m}}$ \\
\hline 14 & SYZS & $34.98 \pm 0.66^{r}$ & $35.97 \pm 0.32^{\text {no }}$ & $42.65 \pm 0.94^{p}$ & $36.77 \pm 0.36^{p}$ & $2.93 \pm 0.060^{r}$ & $2.98 \pm 0.038^{\circ}$ & $3.63 \pm 0.091^{n}$ & $3.32 \pm 0.208^{n}$ \\
\hline 15 & $\mathrm{HBHF}$ & $51.64 \pm 0.40^{f}$ & $52.01 \pm 0.01^{d}$ & $57.85 \pm 0.34^{\mathrm{bc}}$ & $53.55 \pm 0.21^{b c}$ & $4.49 \pm 0.065^{\mathrm{cd}}$ & $4.53 \pm 0.084^{\mathrm{cd}}$ & $4.05 \pm 0.051^{\mathrm{hi}}$ & $3.50 \pm 0.162^{m}$ \\
\hline 16 & HBXS & $45.44 \pm 0.51^{1}$ & $48.44 \pm 1.04^{\mathrm{g}}$ & $52.73 \pm 0.56^{\mathrm{hi}}$ & $53.82 \pm 0.96^{\mathrm{bc}}$ & $3.84 \pm 0.061^{1}$ & $3.87 \pm 0.072^{\mathrm{gh}}$ & $4.66 \pm 0.061^{b}$ & $4.09 \pm 0.084^{\mathrm{ef}}$ \\
\hline 17 & HBJS & $42.68 \pm 0.65^{\text {no }}$ & $41.08 \pm 0.43^{k}$ & $40.10 \pm 0.74^{\mathrm{rs}}$ & $33.92 \pm 0.29^{q}$ & $3.21 \pm 0.100^{p}$ & $3.48 \pm 0.061^{\mathrm{n}}$ & $3.14 \pm 0.076^{\mathrm{p}}$ & $2.58 \pm 0.104^{\circ}$ \\
\hline 18 & HBSN & $49.60 \pm 0.61^{g}$ & $50.78 \pm 0.67^{e f}$ & $44.87 \pm 0.47^{\circ}$ & $47.02 \pm 0.79^{\mathrm{ij}}$ & $4.04 \pm 0.088^{\mathrm{ijk}}$ & $4.29 \pm 0.060^{\mathrm{e}}$ & $4.01 \pm 0.051^{\mathrm{ijkl}}$ & $4.40 \pm 0.034^{\mathrm{bc}}$ \\
\hline 19 & HBWH & $49.81 \pm 0.51^{\mathrm{g}}$ & $52.02 \pm 0.90^{d}$ & $57.55 \pm 0.30^{\mathrm{cd}}$ & $51.36 \pm 0.13^{e f}$ & $4.25 \pm 0.053^{d}$ & $3.70 \pm 0.063^{\mathrm{jk}}$ & $3.80 \pm 0.062^{\mathrm{m}}$ & $4.35 \pm 0.047^{b c}$ \\
\hline 20 & XSSC & $45.98 \pm 0.33^{\mathrm{kl}}$ & $48.37 \pm 0.33^{g}$ & $49.85 \pm 0.68^{j k}$ & $47.31 \pm 0.17^{i}$ & $3.82 \pm 0.034^{\mathrm{kl}}$ & $3.57 \pm 0.041^{1 \mathrm{mn}}$ & $3.91 \pm 0.017^{\mathrm{jklm}}$ & $3.31 \pm 0.275^{n}$ \\
\hline 21 & HBJM & $34.48 \pm 0.40^{r}$ & $35.29 \pm 0.52^{\circ}$ & $31.45 \pm 0.30^{t}$ & $26.60 \pm 0.45^{s}$ & $1.63 \pm 0.021^{u}$ & $1.81 \pm 0.152^{q}$ & $1.32 \pm 0.089^{s}$ & $1.21 \pm 0.006^{s}$ \\
\hline 22 & HBXG & $54.93 \pm 0.65^{c d}$ & $47.14 \pm 0.26^{\mathrm{hi}}$ & $56.60 \pm 0.54^{\text {de }}$ & $53.57 \pm 0.45^{\mathrm{bc}}$ & $4.21 \pm 0.065^{\mathrm{ef}}$ & $3.95 \pm 0.082^{g}$ & $4.61 \pm 0.076^{\mathrm{bc}}$ & $4.45 \pm 0.143^{b}$ \\
\hline 23 & HBMC & $46.88 \pm 0.47^{\mathrm{ij}}$ & $41.81 \pm 0.69^{k}$ & $48.30 \pm 0.78^{1 \mathrm{~m}}$ & $41.64 \pm 0.37^{\mathrm{m}}$ & $4.39 \pm 0.060^{\mathrm{ab}}$ & $3.51 \pm 0.053^{\mathrm{mn}}$ & $4.81 \pm 0.076^{a}$ & $2.07 \pm 0.023^{p}$ \\
\hline 24 & HBLT & $53.95 \pm 0.71^{d}$ & $57.50 \pm 0.67^{b}$ & $50.61 \pm 0.23^{j}$ & $51.56 \pm 0.45^{\mathrm{e}}$ & $4.33 \pm 0.078^{f}$ & $4.72 \pm 0.035^{b}$ & $4.06 \pm 0.035^{\mathrm{ghi}}$ & $4.15 \pm 0.056^{\text {de }}$ \\
\hline 25 & HBSY & $38.33 \pm 0.43^{p}$ & $36.48 \pm 0.64^{\text {no }}$ & $40.79 \pm 0.36^{\mathrm{qr}}$ & $43.92 \pm 0.20^{l}$ & $2.92 \pm 0.011^{p q}$ & $2.59 \pm 0.054^{p}$ & $3.13 \pm 0.073^{p}$ & $3.64 \pm 0.0673^{\mathrm{klm}}$ \\
\hline 26 & AHBZ & $55.85 \pm 0.47^{c}$ & $49.67 \pm 0.39^{f}$ & $59.02 \pm 0.56^{a}$ & $52.44 \pm 0.21^{d}$ & $4.31 \pm 0.046^{\mathrm{e}}$ & $4.29 \pm 0.061^{\mathrm{e}}$ & $4.02 \pm 0.065^{\mathrm{ijk}}$ & $4.28 \pm 0.036^{\mathrm{cd}}$ \\
\hline 27 & JSNJ & $48.03 \pm 0.27^{h}$ & $49.92 \pm 0.75^{e f}$ & $51.87 \pm 0.20^{i}$ & $54.02 \pm 0.31^{b}$ & $4.18 \pm 0.044^{g h}$ & $4.47 \pm 0.033^{d}$ & $4.90 \pm 0.073^{a}$ & $5.00 \pm 0.014^{\mathrm{a}}$ \\
\hline 28 & SXXX & $40.98 \pm 0.78^{\circ}$ & $46.39 \pm 0.46^{h i}$ & $49.05 \pm 0.62^{\mathrm{kl}}$ & $26.94 \pm 0.35^{s}$ & $2.38 \pm 0.090^{t}$ & $2.60 \pm 0.061^{p}$ & $2.83 \pm 0.242^{q}$ & $1.71 \pm 0.098^{q}$ \\
\hline 29 & HNLS & $33.42 \pm 0.35^{\mathrm{s}}$ & $35.59 \pm 0.28^{\text {no }}$ & $31.38 \pm 0.36^{t}$ & $28.73 \pm 0.22^{r}$ & $2.84 \pm 0.045^{r}$ & $2.56 \pm 0.044^{\mathrm{p}}$ & $2.65 \pm 0.044^{r}$ & $2.13 \pm 0.083^{p}$ \\
\hline 30 & HNSZ & $33.37 \pm 0.35^{s}$ & $38.48 \pm 0.33^{m}$ & $29.16 \pm 0.96^{u}$ & $21.58 \pm 0.24^{t}$ & $3.49 \pm 0.050^{\circ}$ & $3.74 \pm 0.026^{\mathrm{ij}}$ & $4.05 \pm 0.070^{h i j}$ & $3.20 \pm 0.025^{n}$ \\
\hline 31 & HBWF & $47.15 \pm 0.78^{h i j}$ & $57.96 \pm 0.64^{b}$ & $53.90 \pm 0.48^{g}$ & $55.23 \pm 0.07^{a}$ & $4.14 \pm 0.067^{a b}$ & $2.63 \pm 0.062^{p}$ & $4.57 \pm 0.038^{b c}$ & $4.11 \pm 0.088^{\mathrm{ef}}$ \\
\hline 32 & SCLS & $52.94 \pm 0.94^{\mathrm{e}}$ & $52.28 \pm 0.71^{d}$ & $50.34 \pm 0.10^{j}$ & $44.95 \pm 0.32^{k}$ & $4.21 \pm 0.071^{\mathrm{fg}}$ & $4.30 \pm 0.051^{\mathrm{e}}$ & $4.18 \pm 0.047^{f g h}$ & $3.72 \pm 0.036^{\mathrm{jkl}}$ \\
\hline 33 & SXZP & $59.03 \pm 0.36^{a}$ & $53.54 \pm 0.78^{c}$ & $58.74 \pm 0.33^{a b}$ & $51.74 \pm 0.55^{\mathrm{e}}$ & $4.58 \pm 0.064^{b c}$ & $4.61 \pm 0.089^{b c}$ & $3.99 \pm 0.068^{\mathrm{ijkl}}$ & $3.57 \pm 0.084^{\mathrm{lm}}$ \\
\hline
\end{tabular}

No. 1-28 are B. striata, No. 29-33 are B. ochracea. Red represents the top five populations in terms of active ingredient contents in different years, while green represents the last five populations. Values represent the mean \pm SD of three biological replicates, and different lowercases letters with superscript indicate significant differences between populations with the parameter of $P<0.05$.

\section{Declarations}




\section{Ethics approval and consent to participate}

Not applicable

\section{Consent for publication}

Not applicable

\section{Availability of data and materials}

All data generated or analysed during this study are included in this published article [and its supplementary information files].

\section{Competing interest}

The authors declare that they have no conflict of interests.

\section{Funding}

This work was supported by the National Natural Science Foundation of China [grant number 31771871]; Biological Resources Program, Chinese Academy of Sciences [grant numbers KFJ-BRP-007, KFJ-BRSN-2018-6-002].

\section{Authors' contributions}

JH: Writing - Original Draft, Writing - Review \& Editing, Visualization. FY: Investigation, Formal analysis. MZ: Validation. TH: Investigation. YZ: Supervision. QL: Conceptualization, Methodology, Resources. All data were generated in-house, and no paper mill was used. All authors agree to be accountable for all aspects of work ensuring integrity and accuracy.

\section{Acknowledgements}

Not applicable

\section{References}

1. Chen XQ, Gale SW, Cribb PJ (2009) Flora of China, Vol. 25, pp 209-210.

2. Li L, Liu HB, Wen WE, Huang CY, Li XM, Xiao SJ, Wu MK, Shi JH, Xu DL. Full transcriptome analysis of callus suspension culture system of Bletilla striata. Front Genet. 2020;11:995. https://doi.org/10.3389/fgene.2020.00995

3. Zhang YJ, Sun W, He Y, Wang SH, Wang Q, Yuan F, Yang LL, Liang Q. Current situation and prospect of resource evaluation and sustainable utilization on Bletilla. Zhongguo Zhong Yao Za Zhi. 2018;43:4397-4403. https://doi.org/10.19540/j.cnki.cjcmm.20180821.001

4. He XR, Wang XX, Fang LC, Zhao ZF, Huang LH, Guo H, Zheng XH. Bletilla striata: Medicinal uses, phytochemistry and pharmacological activities. J Ethnopharmacol. 2017;195:20-38. https://doi.org/10.1016/j.jep.2016.11.026

5. Xu DL, Pan YC, Chen JS. Chemical constituents, pharmacologic properties, and clinical applications of Bletilla striata. Front Pharmacol. 2019;10:1168. https://doi.org/10.3389/fphar.2019.01168

6. Zhang JQ, Zhou T, Xiao CH, Jiang WK, Guo LP, Wang X. Bletilla striata ecological planting patterns and technical principle analysis. Zhongguo Zhong Yao Za Zhi. 2020;45:5042-5047 https://doi.org/10.19540/j.cnki.cjcmm.20200707.102

7. Zhang GY, Huang L, Wu J, Liu YR, Zhang ZL, Guan QX. Doxorubicin-loaded folate-mediated pH-responsive micelle based on Bletilla striata polysaccharide: Release mechanism, cellular uptake mechanism, distribution, pharmacokinetics, and antitumor effects. Int J Biol Macromol. 2020;164:566577. https://doi.org/10.1016/j.ijbiomac.2020.07.123

8. Chen G, Chang WH, Li XZ, Han LZ, Zhou D, Feng Y, Li BX, Zhu FY, Li N. n-BuOH extract of Bletilla striata exerts chemopreventive effects on lung against $\mathrm{SiO} 2$ nanoparticles through activation of Nrf2 pathway. Phytomedicine. 2021;82:153445. https://doi.org/10.1016/j.phymed.2020.153445

9. Jiang S, Wang MY, Jiang L, Xie Q, Yuan HW, Yang YP, Zafar S, Liu Y, Jian YQ, Li B, Wang W. The medicinal uses of the genus Bletilla in traditional Chinese medicine: A phytochemical and pharmacological review. J Ethnopharmacol. 2021;280:114263. https://doi.org/10.1016/j.jep.2021.114263

10. Qu Y, Li CX, Zhang C, Zeng R, Fu CM. Optimization of infrared-assisted extraction of Bletilla striata polysaccharides based on response surface methodology and their antioxidant activities. Carbohydr Polym. 2016;148:345-353. https://doi.org/10.1016/j.carbpol.2016.04.081

11. Niu JF, Zhao GM, Mi ZY, Chen LJ, Liu S, Wang SQ, Wang DH, Wang ZZ. De novo sequencing of Bletilla striata (Orchidaceae) transcriptome and identification of genes involved in polysaccharide biosynthesis. Genet Mol Biol. 2020;43:e20190417. https://doi.org/10.1590/1678-4685-GMB-2019-0417

12. Chen ZY, Zhao Y, Zhang MK, Yang XF, Yue PX, Tang DK, Wei XL. Structural characterization and antioxidant activity of a new polysaccharide from Bletilla striata fibrous roots. Carbohydr Polym. 2020;227:115362. https://doi.org/10.1016/j.carbpol.2019.115362

13. Liu YR, Sun C, Zhang GY, Wu J, Huang L, Qiao J, Guan QX. Bio-responsive Bletilla striata polysaccharide-based micelles for enhancing intracellular docetaxel delivery. Int J Biol Macromol. 2020;142:277-287. https://doi.org/10.1016/j.ijbiomac.2019.09.099

14. Zhao Y, Wang QB, Yan S, Zhou J, Huang LY, Zhu HT, Ye F, Zhang YH, Chen L, Chen L, Zheng T. Bletilla striata Polysaccharide Promotes Diabetic Wound Healing Through Inhibition of the NLRP3 Inflammasome. Front Pharmacol. 2021;12:659215. https://doi.org/10.3389/fphar.2021.659215 
15. Zhou D Chang WH, Liu B, Chen G, Yang YQ, Hao YT, Hou Y, Li N. Stilbenes from the tubers of Bletilla striata with potential anti-neuroinflammatory activity. Bioorg Chem. 2020;97:103715. https://doi.org/10.1016/j.bioorg.2020.103715

16. Sun MH, Ma XJ, Shao SY, Han SW, Jiang JW, Zhang JJ, Li S. Phenanthrene, 9,10-dihydrophenanthrene and bibenzyl enantiomers from Bletilla striata with their antineuroinflammatory and cytotoxic activities. Phytochemistry. 2021;182:112609. https://doi.org/10.1016/j.phytochem.2020.112609

17. Yang C, Xia T, Wang CQ, Sun HY, Li YJ, Gong ZP, Li YT, Zheng L, Huang Y. Using the UPLC-ESI-Q-TOF-MS(E) method and intestinal bacteria for metabolite identification in the nonpolysaccharide fraction from Bletilla striata. Biomed Chromatogr. 2019;33:e4637. https://doi.org/10.1002/bmc.4637

18. Zhang XQ, Zhou T, Xiao CH, Yang CG, Jiang WK, Yu J, Zhang HJ. Quality comprehensive evaluation of Bletilla striata with different producing areas from Guizhou. Zhong Yao Cai. 2020;43:368-373. https://doi.org/10.13863/j.issn1001-4454.2020.02.023

19. Liu JM, An LL, Liu G, Liu YC. Research progress on chemical composition and pharmacological effects of Bletilla striata and predictive analysis on quality marker. Zhonghua Zhong Yi Yao Xue Kan. 2021;39:28-37. https://doi.org/10.13193/j.issn.1673-7717.2021.06.006

20. Moloney KA, Holzapfel C, Tielbrger K, Jeltsch F, Schurr FM. Rethinking the common garden in invasion research. Perspect Plant Ecol Evol Syst. 2009;11:311-320. https://doi.org/10.1016/j.ppees.2009.05.002

21. Penton PM, Davoren GK. A common garden experiment on capelin (mallotus villosus) early life history stages to examine use of beach and deep-water spawning habitats. J Exp Mar Biol Ecol. 2013;439:54-60. https://doi.org/10.1016/j.jembe.2012.10.009

22. Liang Q, Zhang YJ, Chen JJ, Huang HW, Wang Y. Quality variation of ten geographic populations of epimedium sagittatum as evaluated in common garden practice. Genet Resour Crop Evol. 2016; 63:733-743. https://doi.org/10.1007/s10722-016-0369-0

23. Yang LL, Liang Q, Wang SH, Yuan F, He Y. Quality evaluation of thirteen geographical populations of Lycium chinense using quantitative analysis of nutrients and bioactive components. J Food Quality. 2019;2019:9714930. https://doi.org/10.1155/2019/9714930

24. Wang YP, Cui YL, Huang L, Yang MM, Tian J. Quality evaluation of Lycii Fructus based on grey incidence degree method. Mod Chin Med. 2020;22:18511862. https://doi.org/10.13313/j.issn.1673-4890.20200508006

25. Schober P, Boer C, Schwarte LA. Correlation coefficients, appropriate use and interpretation. Anesth Analg. 2018;126:17631768. https://doi.org/10.1213/ane.0000000000002864

26. Lu HX, Tang DB, Wu ZD, Luo K, Han X, Jiang F, Luo YL, Zhang XY, Zhang K, Wang JC. Genotypic variation and environmental effects on yield, quality and agronomic traits of sweet potato. Zhongguo Sheng Tai Nong Ye Xue Bao. 2015;23:158-1168. https://doi.org/10.13930/j.cnki.cjea.150363

27. Naim-Feil E, Pembleton LW, Spooner LE, Malthouse AL, Miner A, Quinn M, Polotnianka RM, Baillie RC, Spangenberg GC, Cogan NOI. The characterization of key physiological traits of medicinal cannabis (Cannabis sativa L.) as a tool for precision breeding. BMC Plant Biol.

2021;21(1):294. https://doi.org/10.1186/s12870-021-03079-2

28. Chen J, Yan T, Jia JM. Research on HPLC fingerprint of Blerillae Rhizoma from multiple provinces. Zhong Guo Yi Yuan Yong Yao Ping Jia Yu Fen Xi. 2017;17:218-221. https://doi.org/10.14009/j.issn.1672-2124.2017.02.026

29. Zhu XY, Zi SH, Wang JJ, Wang L, Shi YN, Qian JX, Ji PZ. Histochemistry localization and content determination for polysaccharide in Bletilla striata and two related species. Zhong Yao Cai. 2018;41:2774-2778. https://doi.org/10.13863/j.issn1001-4454.2018.12.009

30. Mousavi S, Rosa R, Moukhli A, Riachy ME, Mariotti R, Torres M, Pierantozzi P, Stanzione V, Mastio V, Zaher H, Antari AE, Ayoub S, Dandachi F, Youssef H, Aggelou N, Contreras C, Maestri D, Belaj A, Bufacchi M, Baldoni L, Leon L. Plasticity of fruit and oil traits in olive among different environments. Sci Rep. 2019;9:16968. https://doi.org/10.1038/s41598-019-53169-3

31. Wu FY, Qiu LS, Cui XM, Zhang CY, Peng G, Wang CX, Guan HL, Yang Y. Research on influence factors of quality characteristics of Bletilla Striata. Chin Hosp Pharm J. 2016;36:1838-1844. https://doi.org/10.13286/j.cnki.chinhosppharmacyj.2016.21.03

32. Zhang JC, Sun C, Li CZ, Zhou Y, Yang JW, Wang Y, Xiong PF. Study on soil organic matter, enzyme activity and the effective components of Bletilla striata under different planting years. Zhong Yao Cai. 2020;431:7-10. https://doi.org/10.13863/j.issn1001-4454.2020.01.001

33. Ainsworth EA, Gillespie KM. Estimation of total phenolic content and other oxidation substrates in plant tissues using Folin-Ciocalteu reagent. Nat Protoc. 2007;2:875-877. https://doi.org/10.1038/nprot.2007.102

\section{Figures}




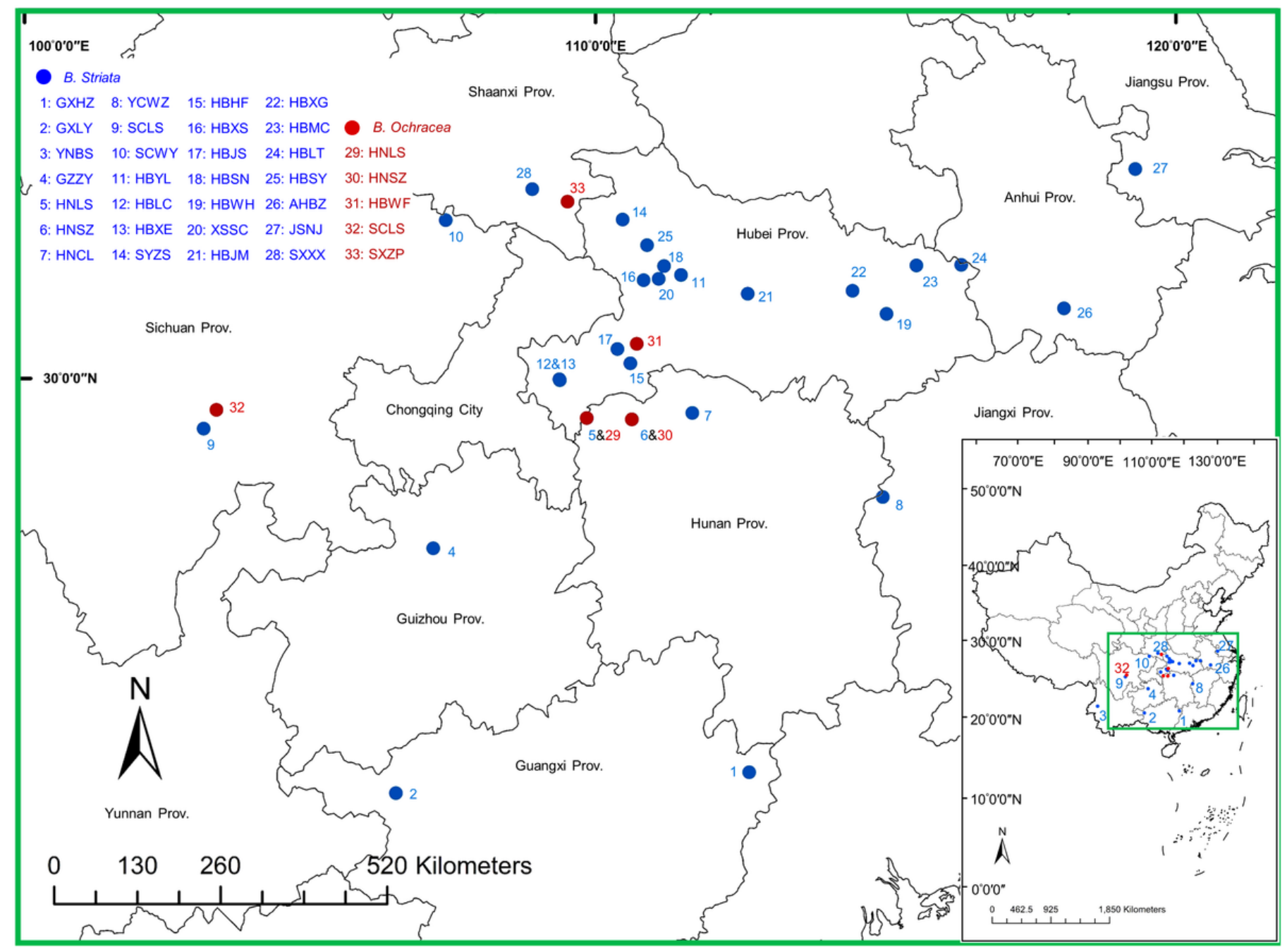

Figure 1

Geographic distribution of the Bletilla plants collected from China. The 33 populations of Bletilla across ten provinces in China. For location details, see Additional file 1. This map was drawn by ArcGIS software based on longitude and latitude in population information. No. 1-28 are populations of B. striata (in blue), while No. 29-33 are populations of B. ochracea (in red). 

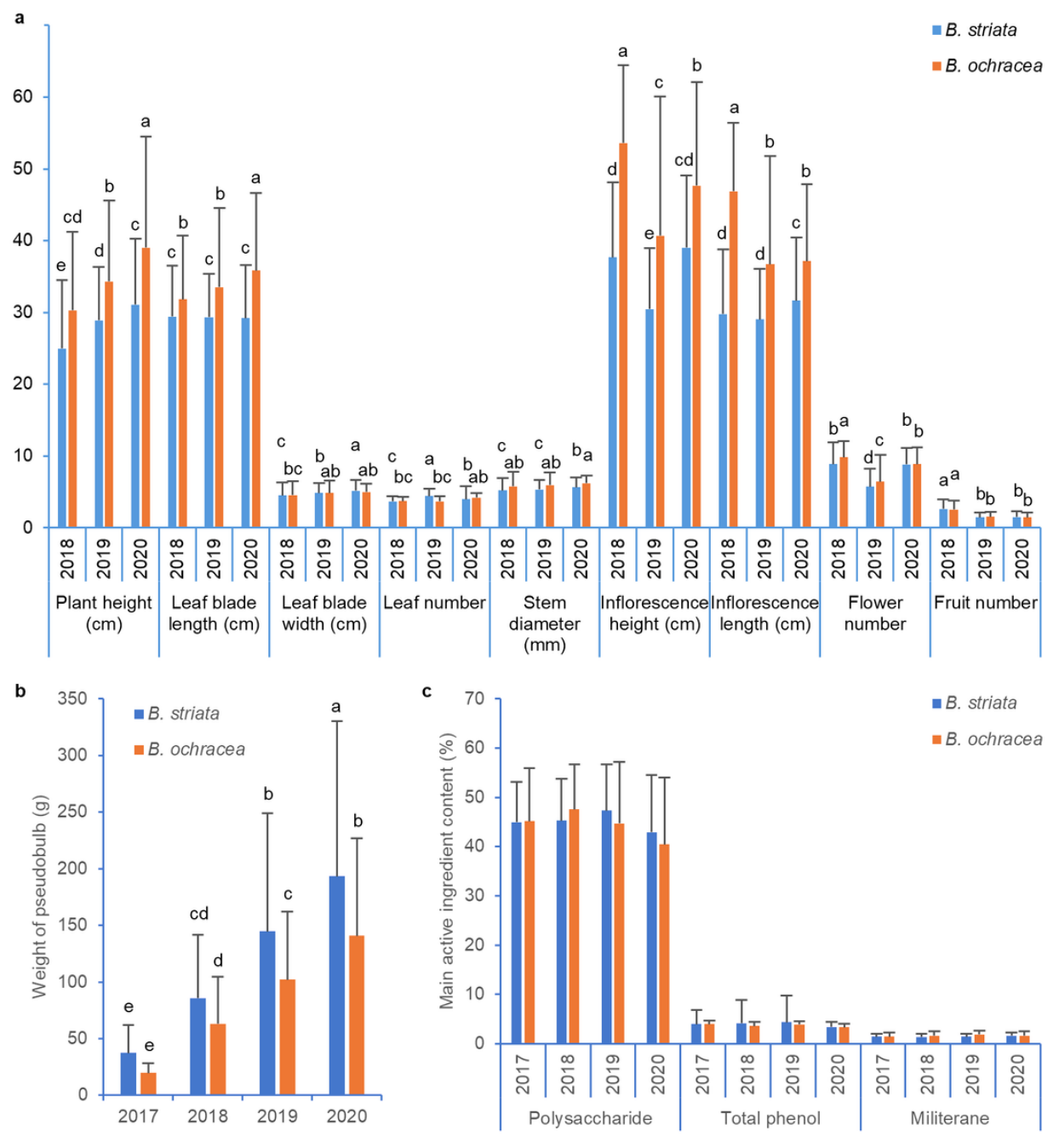

Figure 2

Summary of morphological measurements, pseudobulb weight and main active ingredient content of B. striata and B. ochracea. Comparison of morphological measurements (a), pseudobulb weight (b) and the main active ingredient contents (c) in different growth stages and different species of B. striata and B. ochracea. Values are the mean \pm SD (standard deviation), and different lowercase letters indicate significant differences with the parameter of $P$ $<0.05$. 

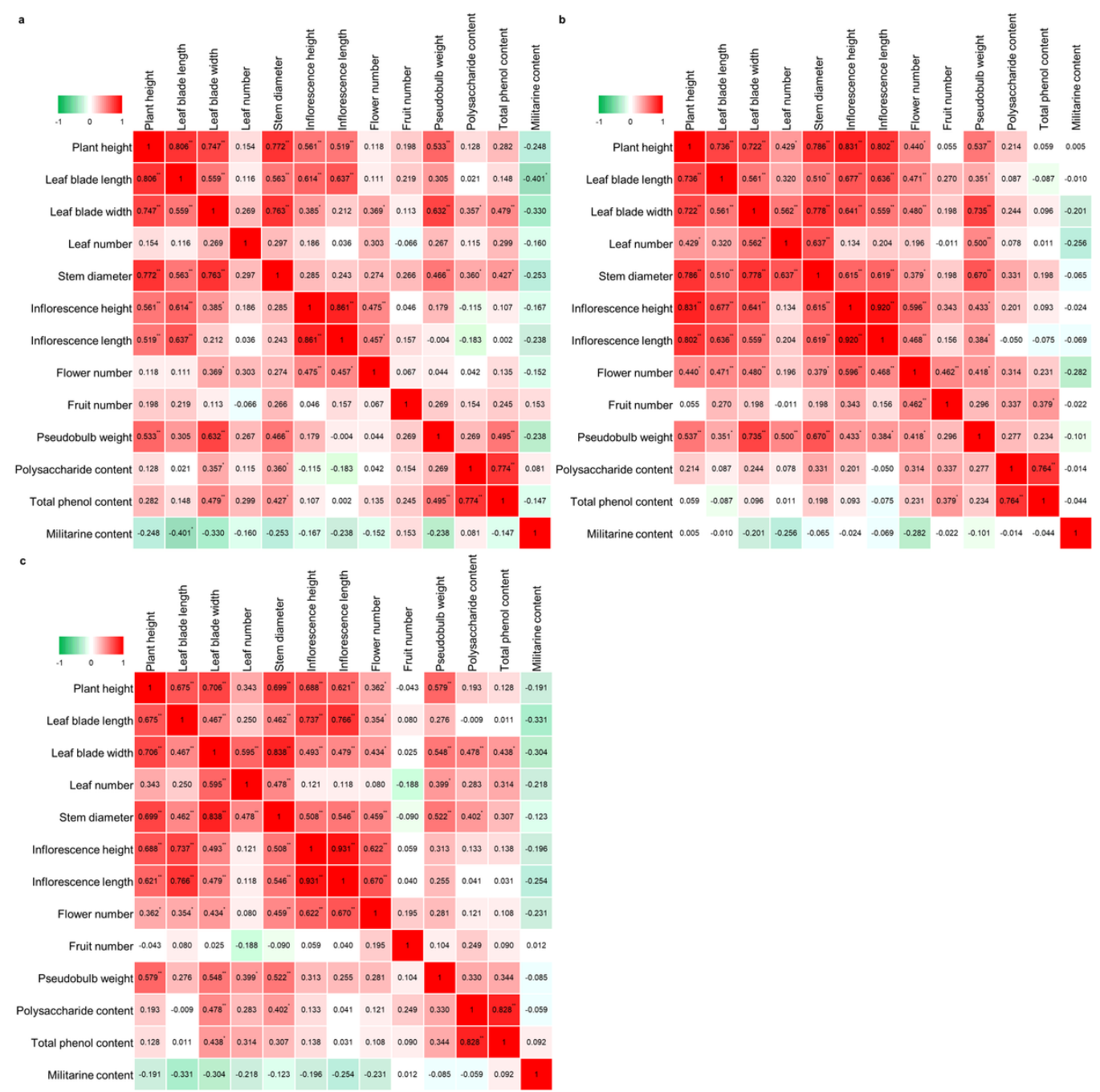

$$
\text { I }
$$

.

\section{Figure 3}

Correlation analysis of phenotypic traits, pseudobulb weight and active ingredient contents. Correlation analysis of phenotypic traits, pseudobulb weight and main active ingredient contents in 2018 (a), 2019 (b) and 2020 (c) was carried out. Values are Pearson correlation coefficients, which are used to construct the heat map. * or ** represent a significant difference with the parameters of $P<0.05$ and $P<0.01$, respectively.

\section{Supplementary Files}

This is a list of supplementary files associated with this preprint. Click to download.

- Additionalfile1.xlsx

- Additionalfile2.xlsx 